Japanese Psychological Research

1968, Vol. 10, No. 1, 13-30

\title{
THE RELATIONSHIP BETWEEN THE LEADER'S MODES OF INTERPERSONAL COGNITION AND THE PERFORMANCE OF THE GROUP
}

\author{
HISAHIRO SHIMA ${ }^{1}$
}

Kyoto University

\begin{abstract}
Three experiments were so designed to examine the effects of leader's modes of interpersonal cognition upon the appropriateness of his role-taking and upon the group-performance. In Experiment I the validity of Fiedler's ASo-Contingency Model was generally supported. In Experiment II \& III we elaborated two more indices-DP- \& DN-scores, which represent the variability of leader's cognition, and classified our leaders into 8 types on the basis of the three indices; DP, DN, \& ASo. The experimental results revealed that the variability of leader's cognition had positive effects on his discriminative and predictive ability and on the appropriateness of his undertaking of leadership. The necessity of making clear the interrelationship between ASo-Contingency Model and the cognitive variability was suggested.
\end{abstract}

As a general theory in leadership research, Fiedler's (1964, 1967) Contingency Model is unique. He proposed so called ASo (=assumed similarity between opposites) score to categorize the leaders' types of cognitions (Fiedler, 1958), and found that the leader who perceives his most and least preferred coworkers as strongly different (in his operational terms, a large discrepancy score leader=low ASo leader) can effectively manage in either very favorable or very unfavorable grouptask situations, whereas the leader who perceives between these two opposites as very similar (a small discrepancy score leader=high ASo leader) can effectively manage in moderately unfavorable grouptask situations (Fiedler, 1964).

According to his theory, there is, in general, a favorableness of group-task situa-

1 The author wishes to thank Prof. Taro Sonohara, Kyoto University, for his helpful suggestions and advices offered throughout the course of the research. In addition, with grateful acknowledgment to $\mathrm{Mr}$. H. Tsuji, The Institute for Child Welfare in Kyoto City, to Mr. Y. Mukai, University of Osaka Prefecture, and to Mr. M. Yabuuchi, Kyoto University, for their helpful criticisms. tion for any task-oriented group, and the effects of the leader's ASo score on the group effectiveness are influenced by the favorableness. The favorableness of the group-task situation is determined in three important dimensions. They are (1) position power inherent in the leadership, (2) the degree to which the task is structured, and (3) the affective relation between the leader and his members (Fiedler, 1967). It is also considered that the interaction of these dimensions is complicated. The operational definition of the favorableness continuum, along with measurement of the three dimensions and the ordering procedure, is detailed by Fiedler (1964, 1967). Median correlations between ASo (or $\mathrm{LPC}^{2}$ ) and group effectiveness scores, plotted in relation to the favorableness continuum, yielded a negative U-shaped curve (Fiedler, 1964, 1967). Fiedler (1966) and Shaw \& Blum (1966) examined experi-

2 The LPG score is one component of ASo and is obtained by simply summing up the item scores on the least preferred coworker scale sheet. ASo scores and LPC scores are highly correlated (Fiedler, 1967: $r=0.80$ to 0.90 ). Therefore, Fiedler has used chiefly LPC scores in his studies since 1962. 
mentally the validity of Fiedler's Contingency Model. Their experimental results supported the hypotheses derived from the model.

Yet we'd like to maintain with Steiner (1964) that, in order to make their results more adequate, it is necessary to make clear experimentally the psychological meaning of ASo score and to examine how the leader's traits measured on ASo scale would be realized in his actual behavior in group situations.

All that Fiedler (1967) states is that low ASo (or L.PC) leaders are concerned with achieving success on assigned tasks, while high ASo (or LPC) leaders are concerned with having good interpersonal relations. Fiedler (1964) examined the co-relations between ASo scores and the scores of a number of personality tests only to find the significant correlations merely in regards to two dimensions of behavioral traits ("Consideration" and "Initiating Structure").

In order to make clear the psychological meaning of ASo score and thus to make ASo more predictable in regards to the subject's group behavior, we propose to let the subject select more than one of his most preferred coworkers to evaluate, and more than one of his least preferred coworkers. In fact a person has a number of his preferred coworkers and a number of his non-preferred coworkers. Therefore, we can make our subject rate all his preferred and non-preferred coworkers on ASo scales, so that we can infer the distributions of these rated scores. These distributions, we assume, are indicative of the variability of the subject's cognition. Fiedler's ASo-score can not show exactly such variability of individual's cognition, because the rated scores of MPC and LPC are only the extreme representatives of his preferred and non-preferred coworkers respectively. Such variability of a leader's cognition is very probable to lead different modes of leadership behaviors and thus to have different effects on his group effective- ness. For these reasons, the ASo score should be considered to have some weakness as the indicator of leader's modes of leadership behavior.

For example let's examine the low ASo leaders more closely. The low ASo leaders perceives his most and least preferred coworkers as strongly different. However, the leader who can distinguish each of his preferred and non-preferred coworkers, while discriminating between his MPC and LPC, would be assumed to recognize the variety of others and to be able to control his coworkers more appropriately. On the other hand, the leader who evaluate all his preferred (and non-preferred) coworkers as very similar, while setting all his preferred against all his non-preferred coworkers, will have some rigidity in viewing his coworkers and so in controlling them. The former can be assumed to be able to recognize his roles in the task situation more appropriately and to behave more controllingly and more managingly, because the variability of his interpersonal cognition will be generalized to his cognition of the task situations. In contrast with this, the latter can be assumed to be in the risk of undertaking his role (=leadership behavior) more coercively and more authoritatively and causing frictions between him and his coworkers because of his fixed viewpoint toward his coworkers and toward the task situation.

Thus we maintain that the ASo score can be more powerful indicator of actual leadership behaviors when it is combined with the variability of his cognition. In this study, letting our subjects (=leaders) to select not only his MPC and LPC, but also all of his preferred coworkers and nonpreferred coworkers to rate on ASo scale, we examine the effects of ASo score and the variability on the leadership behavior and group effectiveness. We maintain that the variability of the leader's cognition (the breadth of his rating scores) will be reflected in his predictive accuracy about his coworkers' behaviors and abilities to 
perform the task. As to this hypothesis, we will test it in the Experiment II-2.

If we use three indices of leader's type of cognition: the ASo score, the breadth of rating scores about some of his preferred coworkers (called DP for short), the breadth of rating scores about some of his non-preferred coworkers (called DN for short), it is possible to classify theoretically the leader's type of cognition into eight classes (See Table 10).

Three experiments were performed in this study. Experiment I was so designed as to find out the intercorelations between the leader's ASo and the group performance in Guilford-type task situation. In Experiment II and III we had two main purposes; (a) to test whether or not there are in fact eight types of leader's interpersonal cognition described above (Experiment II-1); (b) to examine which of these leader's types would be the most effective on the group performance in the task situation where leader's ASo score has no effectiveness in Experiment I (Experiment III).

\section{EXPERIMENT I}

The purpose of this experiment is to examine the effects of ASo mediated by the group-task favorableness on group performance. The group-task favorableness was manipulated by means of task structure only. To manipulate the task-structuredness, two tasks of Guilford-type ("idea" task and "integration" task) were provided with. The "idea" task is easier to solve and thus structured than the "integration" task. As the group-task favorableness is manipulated by task structure, we may say that "idea " task conditions are moderately favorable, while "integration" task conditions are relatively unfavorable. The following hypotheses derived from the Contingency Model were tested with respect to the performance of the group. (1) In "idea" task situation, high ASo leader is more effective than low ASo leader for the group performance. (2) In "integration" task situation, low ASo leader is more effective than high ASo leader for the group performance.

Two types of intergroup competitiveness (intergroup competitive situations v.s. intergroup non-competitive situations) were introduced. This experiment was done as a part of researches for group creativity, and the intergroup competitiveness was primarily treated as a variable which has the effect on group creativity. So this variable has no theoretical connection with the effects of ASo. But we assume that this variable might influence the grouptask favorableness.

According to Fiedler the following hypotheses could be made concerning the relations between leader's ASo score and his group behavior. (3) The followers perceive that low ASo leaders behave more task-orientedly than high ASo leaders. (4) The followers perceive that high ASo leaders behave more member-orientedly than low ASo leaders.

\section{Method}

Subjects. The $S$ s were 128 male highschool students in Kyoto, randomly assigned to 32 four-member groups. Eight groups worked under the condition of "idea " task and intergroup competitive, 8 under "idea" and noncompetition, 8 under " integration" task and competition, and 8 under "integration" and non-competitive condition.

Tasks. The groups were assigned either "idea" task or "integration" task. (a) "Idea " task. Sixteen groups were imposed on two kinds of "idea" tasks, which required to produce as many ideas as possible. Task A required the groups to give the unusual uses of a brick and Task B asked to think of what would be able to do if he were an unvisible man. 15 minutes on each task were allowed for the discussion, and the number of ideas produced was measured. (b) "Integration" task. Other 16 groups were asked to make a story by using ten hardly related words ("flag ", "flatfish ", " answer", "cotton", etc.). The Ss were 
required to make their stories as novel, fresh, and integrated as possible. 30 minutes were allowed for the discussion, and the story was evaluated by ten raters as to novelty, originality, and interestingness.

Intergroup competitiveness. This condition was introduced by the instructions. 16 groups were worked under intergroup competitive situations and the other 16 under non-competitive. The two sets of instructions are as follows. Intergroup competitive condition; The purpose of this study is to investigate how to arrange the group members and group conditions to make creative productions. So we will evaluate the creativeness of all the groups after this experiment, and each member of less-creative group shall be assigned the intelligence test and the personality tests, and be interviewed for a short time. Intergroup non-competitive condition; The groups under non-competitive condition were only told to make as good and creative productions as possible.

Experimental manipulations of group-task favorableness. In this experiment, affective leadermember relations between $S$ s were moderate, and the leader's position power was assumed to be moderately strong because it was assured by his members' election. 'The group-task favorableness variable was manipulated by means of task structure only. From this manipulation, it is clear that the " idea " task situation was moderately favorable and the "integration " task situation was relatively unfavorable.

Measures. (a) Subjects' cognitive ratings of intergroup competitiveness. In order to see how the $S$ s perceive two kinds of group situations, the $S$ s were asked to answer the questionnaire on the following 3 items with a 7-point scale each after the group discussions. (1) Have you been anxious about the performance of the other group? (2) Have you been anxious about the performance of your group? (3) Have you been uneasy in fear that your group should make a poor performance? Correlation coefficients of item analysis (the tetrachoric r) revealed statistical significance at the 0.01 level with each item. (b) Leader's rating of group atmosphere (GA). To examine whether or not the difference of task structures have an effect on the affective leader-member relations, after the group discussions the leaders in each group were asked to describe the group on the following 10 adjective pairs with a 8-point scale each based on Fiedler's GA scale (1962) : friendly-unfriendly; rejecting-accepting; unhelpful-helpful ; nonproductive-productive ; distant-close ; cold-warm ; cooperative-uncooperative ; supportive-hostile ; successfulunsuccessful ; free-restrictive. Correlation coefficients of item analysis (the biserial $r$ ) revealed significance at the 0.01 level with each item. (c) ASo score. Ss rated their most preferred coworker and their least preferred coworker on 8-point scales with the following 14 adjective pairs : pleasant-unpleasant ; friendly-unfriendly; helpful-frustrating ; supportivehostile; cold-warm; quitting-persistent ; stable-unstable ; energetic-tired ; thoughtless-thoughtfull; meek-forcefull; careless -careful ; intelligent-unintelligent ; responsible - undependable ; unenthusiastic-enthusiastic. The biserial $r$ of item analysis revealed the significance at the 0.01 level with each item. The ASo score of each of 32 leaders was computed according to Fiedler's method (1958, p. 16) and was divided into high and low score groups by median cut. For the remainder of this paper, the leader who gives generally higher score in ASo scale (large discrepancy score) will be called "low ASo" leader, while the term "high ASo" leader will denote the leader who rates ASo scale in a generally lower score (small discrepancy). The number of low ASo leaders under each of 4 condition (task $\times$ competitiveness) happened to be 4 , respectively. The number of high ASo leaders, therefore, was equal to that of low ASo leaders for each condition. (d) Leader's function in group-situations. After the group discussions, the followers in each group were asked to answer the questionnaires on their leader's task-orientedness and memberorientedness. The questionnaire on task-orientedness was composed of 4 items with a 7 . point scale each, and the questionnaire on member-orientedness was composed of 5 items with a 7 -point scale each. 4 items concerning 
TABLE 1

Means and standard deviations of Leader's GA scores (Exp. I)

\begin{tabular}{|c|c|c|c|c|c|c|c|c|}
\hline Task & \multicolumn{4}{|c|}{ "Idea" } & \multicolumn{4}{|c|}{ "Integration" } \\
\hline $\begin{array}{l}\text { Intergroup } \\
\text { competitiveness }\end{array}$ & com & titive & non-cc & petitive & com & itive & non-co & petitive \\
\hline ASo & Meant & $S D$ & Mean & $S D$ & Mean & $S D$ & Mean & $S D$ \\
\hline Low ASo leader & 58.25 & 14.93 & 59.00 & 10.03 & 49.00 & 9.128 & 52.00 & 10.24 \\
\hline High ASo leader & 57.50 & 8.262 & 59.25 & 7.275 & 50.25 & 11.15 & 53.00 & 6.056 \\
\hline
\end{tabular}

+ Mean of the 4 leaders.

Note: The variance of all the cells did not significantly differ according to Cochran's method $(G=0.2809, v=3, k=8, p>.05)$.

task-orientedness were: (1) The leader went ahead with the task. (2) The leader took care that the group attained a good task-accomplishment. (3) From the beginning the leader had his own plan to carry out. (4) The leader compelled us to do anything in his way. 5 items concerning member-orientedness were: (1) The leader paid regards to each of our opinions. (2) The leader took care that the members should be friendly with each other. (3) The leader took care that the group members should discuss frankly with each other to the full. (4) The leader allowed us to talk freely with each other. (5) The leader minded so that we might come to agreements at any time. The tetrachoric $r$ of item analysis revealed significance at the 0.01 level with any match of items.

Procedure. The procedure was as follows: (1) Instruction (description of experimental task). (2) The election of the leader by group members. (3) Giving a nickname to the group by its members. (4) Situational manipulation by instructions in regards to intergroup competitiveness (competitive v.s. non-competitive). (5) Group discussion (task accomplishment). (6) Questionnaires after the experiment (ASo scale, leadership rating scale, perceived competitiveness, GA scale).

\section{Results}

I. First of all, it is necessary to examine whether the experimental manipulation was successful or not. In this experiment two variables were experimentally mani- pulated: one is the intergroup competitiveness and the other is the favorableness of task structure. As for the intergroup competitiveness the mean rating score given by $S$ s under intergroup competitive condition was 10.44 under "idea" task and 11.89 under " integration" task, while it was 13.63 under "idea" and 12.39 under "integration" for $S \mathrm{~s}$ under noncompetitive conditions. Analysis of variance approaches but doesn't attain significant $F$ value for intergroup competitiveness $(F=3.40, d f=1 / 124, .10>p>.05)$. None of the other sources of variation attained the statistical significance. It was observed, however, that the experimental manipulation tended to have the expected effects on $S s^{\prime}$ perceptions of competitiveness. When we treat the other results below, therefore, we will deal with intergroup competitiveness as the independent variable, though the above results should be carefully considered.

2. Before examining the results, it is necessary, also, to examine whether the group-task favorableness was successfully manipulated by the task structure. As Fiedler (1967) noted, evidence for this can be obtained from the leader's rating of GA. The rating scores range from 10 (most unfavorable) to 80 (most favorable). Table 1 gives means and standard deviations of the leaders' GA scores. Analysis of variance yielded statistical significant 
TABLE 2

Means and standard deviations of the number of ideas under "idea" task (Exp. I)

\begin{tabular}{|c|c|c|c|}
\hline $\begin{array}{l}\text { Intergroup } \\
\text { competitiveness }\end{array}$ & \multirow{2}{*}{$\begin{array}{l}\text { Competitive } \\
\text { Meant } S D\end{array}$} & \multicolumn{2}{|c|}{$\begin{array}{l}\text { Non-com- } \\
\text { petitive }\end{array}$} \\
\hline ASo & & Mean & $S D$ \\
\hline Low ASo leader & $48.25 \quad 15.59$ & 34.25 & 15.46 \\
\hline High ASo leader & $49.25 \quad 25.27$ & 37.75 & 8.549 \\
\hline
\end{tabular}

+ Mean of the 4 groups.

Note: The variance of all the cells did not signifcantly differ according to Cochran's method ( $G=$ $0.5352, v=3, k=4, p>.05)$.

\section{TABLE 3}

Analysis of variance on means of the number of ideas under "idea" task (Exp. I)

\begin{tabular}{l|rrr}
\hline \multicolumn{1}{c|}{ Source } & df & \multicolumn{1}{c}{$M S$} & \multicolumn{1}{c}{$F$} \\
\hline A. Competitiveness & 1 & 650.25 & 2.19 \\
B. ASo & 1 & 20.25 & $<1$ \\
C. A $\times$ B & 1 & 106.25 & $<1$ \\
$\quad$ Error & 12 & 297.08 & \\
\end{tabular}

$F$ value for kinds of tasks $(F=4.31, d f=1 /$ $24, p<.05)$ and none of the other sources of variation attained the significance. Thus, it can be said that the leader under "idea" task situation perceived the group as more favorable than did the leader under "integration". The difference of tasks appears to have produced the expected difference in group-task favorableness.

3. Group performance. Table 2 shows the mean numbers of ideas produced which were employed as the measures of group performance under "idea " task for intergroup competitiveness and ASo. Analysis of variance revealed that none of all sources of variation attained the statistical significance (Table 3). Hypothesis I was not supported. In addition, the expectation that the groups under competitive conditions were more productive than those under non-competitive conditions was not supported, although the tendency was in the expected directions. Table 4 shows the means and standard deviations of rated
TABLE 4

Means and standard deviations of rated scores as group performance under "integration" task

(Exp. I)

\begin{tabular}{|c|c|c|c|c|}
\hline $\begin{array}{l}\text { Intergroup } \\
\text { competitiveness }\end{array} \rightarrow$ & \multicolumn{2}{|c|}{ Competitive } & \multicolumn{2}{|c|}{$\begin{array}{l}\text { Non-com- } \\
\text { petitive }\end{array}$} \\
\hline$\downarrow^{\text {ASo }}$ & Meant & $S D$ & Mean & $S D$ \\
\hline Low ASo & 49.28 & 10.04 & 55.33 & 9.465 \\
\hline High ASo leader & 32.05 & 19.38 & 35.83 & 11.27 \\
\hline \multicolumn{5}{|c|}{ Mean of the 4 groups. } \\
\hline \multicolumn{5}{|c|}{$\begin{array}{l}\text { Note: The variance of all the cells did not signifi- } \\
\text { cantly differ according to Cochran's method ( } G= \\
0.5421, v=3, k=4, p>.05) \text {. }\end{array}$} \\
\hline
\end{tabular}

TABle 5

Analysis of variance on means of rated scores as group performance under "integration" task

(Exp. I)

\begin{tabular}{lrrc}
\hline \multicolumn{1}{c}{ Source } & $d f$ & \multicolumn{1}{c}{$M S$} & $F$ \\
\hline A. Competitiveness & 1 & 96.53 & $<1$ \\
B. ASo & 1 & 1348.73 & $7.79^{*}$ \\
C. A $\times$ B & 1 & 5.18 & $<1$ \\
$\quad$ Error & 12 & 173.14 &
\end{tabular}

* Significant at the 0.05 level.

scores which was employed as the measures of group performance under "integration" tasks, for all conditions. As Table 5 shows, analysis of variance yielded significant $F$ value for ASo. None of the other sources of variation attained the significance. Thus hypothesis 2 was supported.

4. Leaders' group functions. With respect to the leader's task-orientedness, the means and standard deviations of followers' rating scores are shown in Table 6. As Table 7 shows, significant $F$ values were obtained for tasks and also for the competitiveness $\times$ ASo interaction. $F$ value for ASo was not significant and the hypothesis 3 was not supported. Low ASo leaders don't always be perceived as more taskoriented, more directive than high ASo leaders. Significant $F$ value for tasks suggests that the followers perceived that the leaders under " idea " task were more task- 
The Leader's Modes of Interpersonal Cognition and the Performance of the Group

Table 6

Means and standard deviations of follower's rating scores of leader's task-orientedness (Exp. I) ${ }^{\dagger}$

\begin{tabular}{|c|c|c|c|c|c|c|c|c|}
\hline Task & \multicolumn{4}{|c|}{ "Idea" } & \multicolumn{4}{|c|}{ "Integration" } \\
\hline $\begin{array}{l}\text { Intergroup } \\
\text { competitiveness }\end{array}$ & \multicolumn{2}{|c|}{ Competitive } & \multicolumn{2}{|c|}{ Non-competitive } & \multicolumn{2}{|c|}{ Competitive } & \multicolumn{2}{|c|}{ Non-competitive } \\
\hline ASo & Mean & $S D$ & Mean & $S D$ & Mean & $S D$ & Mean & $S D$ \\
\hline Low ASo leader & 62.50 & 6.137 & 56.00 & 2.707 & 59.00 & 7.164 & 45.25 & 7.805 \\
\hline High ASo leader & 57,50 & 3.697 & 57.25 & 6.994 & 52.50 & 9.110 & 57.00 & 6.377 \\
\hline
\end{tabular}

† Mean scores are the 4 groups' mean of summation scores earned by three followers in each group (possible score is 12 to 84 ).

Note: The variance of all the cells did not significantly differ according to Cochran's method ( $G=$ $0.2416, v=3, k=8, p>.05)$.

\section{TABLE 7}

Analysis of variance on means of follower's rating scores for leader's task-orientedness (Exp. I)

\begin{tabular}{l|rrc}
\hline \multicolumn{1}{c|}{ Source } & $d f$ & \multicolumn{1}{c}{$M S$} & $F$ \\
A. Task & 1 & 190.13 & $4.43^{*}$ \\
B. Competitiveness & 1 & 128.00 & 2.98 \\
C. ASo & 1 & 1.13 & $<1$ \\
D. A $\times \mathrm{B}$ & 1 & 3.13 & $<1$ \\
E. A $\times \mathrm{C}$ & 1 & 40.50 & $<1$ \\
F. $\mathrm{B} \times \mathrm{C}$ & 1 & 300.13 & $6.99^{*}$ \\
G. A $\times \mathrm{B} \times \mathrm{C}$ & 1 & 72.00 & 1.68 \\
$\quad$ Error & 24 & 42.94 &
\end{tabular}

* Significant at the .05 level. oriented than the leaders under "integration" task.

The significant interaction term is very interesting. As for the competitiveness $x$ ASo interaction, closer analysis of variances revealed that the leaders under intergroup competitive were significantly more task-orientedly than the leaders under noncompetitive in low ASo condition ( $F=$ 9.55, $d f=1 / 24, p<.01)$, while that they were not significantly different in effectiveness in high ASo condition $(F<1, d f$ $=1 / 24, p>.10)$. Moreover in competitive condition low ASo leaders were not more task-orientedly than high ASo leaders

TABLE 8

Means and standard deviations of follower's rating scores of leader's member-orientedness (Exp. I) ${ }^{\dagger}$

\begin{tabular}{|c|c|c|c|c|c|c|c|c|}
\hline Task & \multicolumn{4}{|c|}{ "Idea" } & \multicolumn{4}{|c|}{ "Integration" } \\
\hline $\begin{array}{l}\text { Intergroup } \\
\text { competitiveness }\end{array}$ & \multicolumn{2}{|c|}{ Competitive } & \multicolumn{2}{|c|}{ Non-competitive } & \multicolumn{2}{|c|}{ Competitive } & \multicolumn{2}{|c|}{ Non-competitive } \\
\hline$\downarrow^{\text {ASo }}$ & Mean & $S D$ & Mean & $S D$ & Mean & $S D$ & Mean & $S D$ \\
\hline Low ASo leader & 81.50 & 9.255 & 80.25 & 6.396 & 80.50 & 7.000 & 61.50 & 7.724 \\
\hline High ASo leader & 82.50 & 3.000 & 75.25 & 10.27 & 73.75 & 6.396 & 72.25 & 9.912 \\
\hline
\end{tabular}

$\uparrow$ Mean scores are the 4 groups' mean of summation scores earned by three followers in each group (possible score is 15 to 105 ).

Note: The variance of all the cells did not significantly differ according to Cochran's method $(G=$ $0.2159, v=3, k=8, p>.05)$. 
TABLE 9

Analysis of variance on means of follower's rating scores for leader's member-orientedness (Exp. I)

\begin{tabular}{l|rcc}
\hline \multicolumn{1}{c|}{ Source } & $d f$ & $M S$ & $F$ \\
\hline A. Task & 1 & 496.13 & $7.39^{*}$ \\
B. Competitiveness & 1 & 420.50 & $6.26^{*}$ \\
C. ASo & 1 & 0 & $<1$ \\
D. A $\times \mathrm{B}$ & 1 & 72.00 & 1.07 \\
E. A $\times \mathrm{C}$ & 1 & 32.00 & $<1$ \\
F. B $\times \mathrm{C}$ & 1 & 66.13 & $<1$ \\
G. A $\times \mathrm{B} \times \mathrm{C}$ & 1 & 276.13 & 4.11 \\
$\quad$ Error & 24 & 67.13 &
\end{tabular}

* Significant at the .05 level.

$(F=3.08, d f=1 / 24, p>.05)$, and in noncompetitive condition high ASo leaders were not more task-orientedly than low ASo leaders $(F=3.93, d f=1 / 24, p>.05)$. This suggests that the low ASo leader's behaviors were perceived more task-oriented in intergroup competitive situations than in less competitive situations, while high ASo leader's behaviors were moderately task-oriented both in competitive and non-competitive situations.

Table 8 shows the means and standard deviations of follower's rating scores concerning the leader's member-orientedness for all conditions. Analysis of variance (Table 9) yielded two significant values of variations; tasks and intergroup competitiveness. The hypothesis 4 was not supported; that is, Fiedler's assumption that high ASo leaders behave more memberorientedly, more compliantly than low ASo leaders was not supported.

\section{Discussion}

As we stated above, the intergroup competitive and non-competitive situations resulted in no significant difference. So we will discuss chiefly the relationship between the types of ASo and the performance under non-competitive conditions (Hypotheses $1 \& 2$ ). In this experiment the affective relation between the leader and his members, and the position power in- herent in the leadership were controlled to be constant, and only the degree of taskstructuredness was manipulated. The position power of leader was moderate in both kinds of groups, because the leader was not given the right to punish or reward his members, while his position being assured by his members' election. The degrees of task-structuredness were high with " idea" task and low with " integration" task. As to the leader-member relation, leader's GA score proved that it was influenced by the task-structuredness (Table 1): it was moderately good in "idea " task situations while it was moderately bad in "integration" task situations. From these results it is concluded that the task-situation was moderately favorable in "idea" task groups and relatively unfavorable in "integration" task groups. According to Fiedler's Contingency Model leaders' ASo score is expected to have a high negative correlation with the performance of his group in moderately favorable task situation while a high positive correlation is expected in relatively unfavorable task situation (See Footnote 3).

In this experiment we computed the correlation between ASo-scores and group performances to test the above hypotheses. They proved to be $r=-0.26(p>.10)$ in " idea " task situation and $r=0.71(p<.05)$ in "integration" task situation." These results supported the hypothesis for unfavorable task condition but not for favorable task condition. The reason why the hypotheses derived from Fiedler's Contingency Model could not be experimentally supported may due to the incorrectness of his model itself. But it seems that we must first take account for the ambiguity of criteria by which we decided the degree of task-favorableness. In this experiment

\footnotetext{
${ }^{3}$ ASo score used in our study was adversely related to that of Fiedler, because "the discrepancy score" was treated as the ASo score in this study. According to Fiedler this value will be positive, because he regarded the LPC score as the ASo score.
} 
we decided the favorableness with the help of Fiedler's illustrations as well as Shaw's works (1963) concerning kinds of group tasks. But this way may as well be criticized as arbitrary. Therefore, it seems that the above mentioned results show the necessity of precise operational definitions of the three dimensions of group-task favorableness: leader-member relationship, task-structuredness, and leader's position power. Moreover the fact that the GA-scores were significantly affected by task structuredness reveals the necessity of making clear the interdependency of the three dimensions.

Now we will discuss the results concerning the hypotheses $1 \& 2$. First the results supported the hypothesis 2 (Table 5). As we mentioned in the section of "method", the "integration" task situations were relatively unfavorable. So we can derive from Fiedler's Contingency Model the hypothesis that the low ASo leaders are more effective for the group performances than high ASo leaders in "integration" task situations (Hypothesis 2). This hypothesis was statistically supported. On the other hand, hypothesis 1 was not supported (Table 3). Group under high ASo leaders were not significantly more effective than those under low ASo leaders in "idea" task situations assumed as more favorable. The result was the same when we employed, as the index of performance, the number of categories used in the production of ideas instead of the number of ideas. The most likely interpretation for these results will be that the "idea" task situations were not moderately favorable but, at most, moderately unfavorable. Fiedler noted that the negative correlations between ASo scores and the performances were higher in moderately favorable situations than in moderately unfavorable situations, and that the correlation values in the latter cases were about $r=-0.20 \sim-0.30^{4}$

\footnotetext{
4 Signs are reversed to Fiedler's original data (See Footnote 3).
}

(1964, 1967). The correlation value in the present experiment lay just in this range, though not statistically significant, so it might be assumed that the "idea" task situation might have to be rather moderately unfavorable than moderately favorable. Aside from this explanation, however, it seems quite fair to say that the task structuredness and its effects on the favorableness are treated in an oversimplified manner, as discussed by Shaw \& Blum (1966), and that arbitrariness can not be avoided in deciding experimentally the degrees of task structuredness and favorableness.

The above-said result that there yielded no significant differences of performances between the competitive and non-competitive groups in either "ideas" task or "integration" task condition may be caused by the failure of experimental manipulation only by instructions. Difficulty in producing experimental conditions merely with the instructions consists in the fact that the effects of the instruction on the $S_{\mathrm{s}}$ are likely to diminish as the lapse of time. This tendency will grow stronger as the task grows more interesting to the $S \mathrm{~s}$ and the time required for the task-accomplishments are prolonged.

Concerning the leaders' task-orientedness and member-orientedness perceived by their followers, the results are summarized on Table $6,7,8, \& 9$. On the effects of the task-situation ("idea" task v.s. "integration" task) the leaders in "idea" task situations were perceived by their followers as more task-oriented and member-oriented than the leaders in "integration" task situations were. This results are likely to due to the difference of complexity between the two tasks. The "idea" task requires the group members simply to produce as many ideas as possible. So after the group members produce all ideas they think of, they are likely to become silent and the leader have to encourage, by all means, his followers to open their mouths. Thus the leaders in 
"idea " task situations are assumed to have many chances to speak in the course of task accomplishment, and are perceived by the followers as more task-oriented as well as member-oriented. On the other hand the "integration" task consists of a series of many subgoals, and the attainment of an earlier subgoal put the group members working on the activities for the next subgoal and so on. This continuous requirement for the members' goal-attainment activities is likely itself to encourage the members to wrestle with the task. So the leaders in "integration" task situations are assumed to have only to make occasional comments. Thus they are assumed to have been perceived as less task-oriented and less member-oriented.

Next, concerning the effect of intergroup competitiveness on leader's member-orientedness, the result that the leaders in competitive situations were perceived as more member-oriented than the leaders in non-competitive situations will be admitable if we assume the competitive condition brings about a stressful situation. That is, the leaders in competitive situations are required to behave so as to lower his members' anxiety, to reduce their tensions, namely to behave more member-orientedly. On the relationship between leader's ASo score and the scores of his task-orientedness, member-orientedness, the hypotheses that high ASo leaders are more memberoriented and low ASo leaders are more task-oriented were not supported (hypotheses 3 \& 4). But it would be premature to state that this result denies Fiedler's assertion (1967), because the significant interaction between ASo scores and intergroup competitiveness agrees, though partially, to Fiedler's following saying (1967): ". . . The behaviors of highand low-LPC [ASo] leaders will thus be quite different if the situation is such that the satisfaction of their respective needs is threatened. Under these conditions [unfavorable or stressful] the high-LPC [ASo] leader will increase his interpersonal in- teraction in order to cement his relations with other group members while the lowLPC [ASo] leader will interact in order to complete the task successfully...." It can be assumed that the competitive condition was threatening to the low ASo leaders. The reason for which the main effect of ASo-type was not significant in regards to either member-orientedness or task-orientedness seems to be that the effects of other factors, especially that of the kind of task, were too powerful.

\section{EXPERIMENT II}

As discussed in the introduction, we can classify eight types when we take the variability of interpersonal cognition (DP \& DN) as well as ASo into consideration. Differences in the variability of interpersonal cognition was assumed as it reflected the degree of discriminated cognition toward person. If so, it may be proposed that the accuracy in the prediction of other person would be different between the leaders of these different types. In the Experiment II this hypothesis was inquired. First, in the Experiment II-I we would like to examine whether there exists really the proposed 8 types. Secondly, in the Experiment II-2 the following hypotheses were tested. (1) Both DP and DN scores should have significant positive relationship with the accuracy of prediction of the behaviors of both preferred and non-preferred; namely, the person with a wide distribution of DP scores (called high DP for short) should be able to predict the behaviors of his followers more accurately than the person with a narrow distribution of DP scores (called low DP for short) and the person with a wide distribution of DN scores (called high DN for short) should be able to predict the behaviors of his followers more accurately than the person with a narrow distribution of DN scores (called low DN for short). (2) There should be no significant positive relationship between ASo scores and predictive 
Table 10

The leader's type of interpersonal cognition (Exp. II-l)

\begin{tabular}{|c|c|c|c|c|c|c|c|c|}
\hline ASo & \multicolumn{4}{|c|}{ High } & \multicolumn{4}{|c|}{ Low } \\
\hline DP & \multicolumn{2}{|c|}{ High } & \multicolumn{2}{|c|}{ Low } & \multicolumn{2}{|c|}{ High } & \multicolumn{2}{|c|}{ Low } \\
\hline DN & High & Low & High & Low & High & Low & High & Low \\
\hline No. of $S \mathrm{~s}$ & 27 & 22 & 20 & 28 & 23 & 24 & 27 & 23 \\
\hline
\end{tabular}

accuracy.

\section{EXPERIMENT II-1}

\section{Method}

Subjects. The Ss were 194 male highschool students in Osaka.

Meastures. In measuring the DP, DN scores, the number of preferred (or non-preferred) coworkers is very probable to differ among the $S$ s. So, if the number of preferred (or nonpreferred) coworkers to be selected is restricted, the variability measured by $\mathrm{DP}$ - and DNscores will be warped. But if we allow the $S$ s to select as many number of their coworkers as they like, it will make the experimental procedure extraordinarily complicated. Therefore, before the experiment, 100 male students were randomly selected from $S_{\mathrm{s}}$, and were asked to count the number of both preferred and non-preferred coworkers in task situations. The result revealed that each had selected 2 or 3 preferred and non-preferred coworkers. In the light of this result we decided to ask all Ss to think of three most preferred coworkers and three least preferred coworkers whom they had ever worked with. The description of each coworker was made on 8 point bi-polar adjective check-lists, which were just the same as ASo scale in Experiment I. Scores of each coworker were derived by scoring from most to least favorable ( 8 to 1 ) on each of the items and were obtained by simply summing the item scores (possible score is from 14 to 112). DP score of each subject was obtained by simply subtracting the minimum from the maximum of the 3 (or 2) most preferred coworkers' scores. Thus, a person with a low DP score is assumed to take his preferred coworkers as similar (i.e. will have a low variability), while a person with a high DP score is assumed to take his preferred coworke as not so similar (i.e. will have a high variability). The possible DP score will range from 0 to 98 . Similarly, the DN score was obtained by subtracting the minimum from the maximum of the 3 (or 2) least preferred coworkers' scores. We assume that both the DP- and DN-scores show the ability for discrimination in interpersonal cognition. But it also seems probable that there are those who have a low DP score and a high DN score or have a high DP score and a low DN score at a time. The ASo scores were obtained by using the description of both $\mathrm{MPC}$ (the first most preferred coworker) and LPC (the first least preferred coworker) in the same manner as Fiedler (1958, p. 16).

\section{Results}

DP scores, DN scores, and ASo scores, obtained from each of $194 \mathrm{Ss}$, were respectively divided into high- and lowgroups by median cut. The types of interpersonal cognition may be classified into 8 types by combining the three indices of types of interpersonal cognition. As Table 10 shows, $194 S$ s were equally distributed in 8 types. In the sample of $194 \mathrm{Ss}$, ASo score correlated with DP score $r=.025$ and with DN score $r=.022$; DP score and DN score correlated $r=.259$. The first two correlations were very poor, but the last was statistically significant at the 0.01 level. These results show that the ASo score and the other two scores show the different aspects of interpersonal cognition, but that 
TABLE 11

Means and standard deviations of predictive accuracy scores for preferred persons (Exp. II-2)

\begin{tabular}{|c|c|c|c|c|c|c|c|c|c|}
\hline \multirow[t]{3}{*}{ ASo } & \multirow{3}{*}{$\mathrm{DP} \rightarrow$} & \multicolumn{4}{|c|}{ Low } & \multicolumn{4}{|c|}{ High } \\
\hline & & \multicolumn{2}{|c|}{ High } & \multicolumn{2}{|c|}{ Low } & \multicolumn{2}{|c|}{ High } & \multicolumn{2}{|c|}{ Low } \\
\hline & & Meant & $S D$ & Mean & $S D$ & Mean & $S D$ & Mean & $S D$ \\
\hline High & & 4.31 & 1.25 & 2.82 & 1.86 & 4.31 & 2.18 & 3.08 & 1.75 \\
\hline Low & ; & 2.92 & 1.38 & 2.92 & 1.04 & 3.00 & 1.15 & 2.92 & 1.61 \\
\hline
\end{tabular}

+ Mean of $13 \mathrm{Ss}$.

Note: The variance of all the cells did not significantly differ according to Cochran's method $(G=0.2246, v=12, k=8, p>.05)$.

DP and DN scores show comparatively related aspects of interpersonal cognition.

\section{EXPERIMENT II-2}

\section{Method}

Subjects. The Ss were 104 selected so randomly from $194 \mathrm{Ss}$ in Experiment II-1, as each 13 in every cognitive types.

Predictive instrument. To measure the predictive accuracy a questionnaire was used after Bieri (1955). It was consisted of 4 items depicting social situations in which four reasonable behavioral alternatives are presented. Each subject completed this questionnaire by selecting one of the four alternative responses and then were asked to predict the responses of four (two preferred and two non-preferred persons) of his classmates, who had been asked to answer by themselves to the questionnaire. Thus, a total of 16 predictions were made by each subject. Of course, the subject's predictive accuracy would be affected by the degree of familiarity. But, as the $S$ s were asked in this experiment to select their own home-room classmates, they would be considered to be equally familiar with each other. Predictive accuracy scores for preferred and non-preferred persons were separately obtained by summing the number of correct predictions made by the subject on each two persons. The criterion for correctness (correct response) was the agreement of subject's prediction with the responses given by the person.
TABLE 12

Analysis of variance on means of predictive accuracy scores for preferred persons

(Exp. II-2)

\begin{tabular}{l|rrc}
\multicolumn{1}{c}{ Source } & $d f$ & \multicolumn{1}{c}{$M S$} & $F$ \\
\hline A. ASo & 1 & 0.1538 & $<1$ \\
B. DP & 1 & 12.4615 & $5.0459^{*}$ \\
C. DN & 1 & 12.4615 & $5.0459^{*}$ \\
D. A $\times$ B & 1 & 0.0385 & $<1$ \\
E. A $\times$ C & 1 & 0.0385 & $<1$ \\
F. B $\times$ C & 1 & 11.1154 & $4.5009^{*}$ \\
G. A $\times \mathrm{B} \times \mathrm{C}$ & 1 & 0.1538 & $<1$ \\
$\quad$ Error & 96 & 2.4696 &
\end{tabular}

* Significant at the 0.05 level.

In addition, $S$ s were assigned to the intelligence test and YG personality test (Tsujioka, Yatabe, \& Sonohara, 1957), to examine the relationship between ASo, DP, DN scores and these tests.

Results

The scores of predictive accuracy can range from 0 to 8 . Means for preferred and non-preferred persons were 3.29 and 3.13 respectively. The result of $t$-test revealed that the difference of the two was significant $(t=2.858, \quad d f=103, \quad p<.02)$. The prediction for non-preferred persons is more difficult than the prediction for preferred persons. In Table 11 the means and standard deviations of predictive ac- 
TABLE 13

Means and standard deviations of predictive accuracy scores for non-preferred persons (Exp. II-2)

\begin{tabular}{|c|c|c|c|c|c|c|c|c|c|}
\hline \multicolumn{2}{|l|}{ ASo } & \multicolumn{4}{|c|}{ Low } & \multicolumn{4}{|c|}{ High } \\
\hline & \multirow[t]{2}{*}{$\mathrm{DP} \rightarrow$} & \multicolumn{2}{|c|}{ High } & \multicolumn{2}{|c|}{ Low } & \multicolumn{2}{|c|}{ High } & \multicolumn{2}{|c|}{ Low } \\
\hline & & Meant & $S D$ & Mean & $S D$ & Mean & $S D$ & Mean & $S D$ \\
\hline High & & 4.31 & 1.25 & 2.46 & 1.39 & 4.23 & 1.36 & 3.15 & 1.27 \\
\hline Low & & 2.38 & 1.66 & 2.31 & 1.49 & 3.15 & 1.27 & 3.08 & 1.44 \\
\hline
\end{tabular}

+ Mean of $13 \mathrm{Ss}$.

Note: The variance of all the cells did not significantly differ according to Cochran's method $(G=0.1649, v=12, k=8, p>.05)$.

TABLE 14

Analysis of variance on means of predictive accuracy scores for non-preferred persons (Exp. II-2)

\begin{tabular}{|c|c|c|c|}
\hline Source & $d f$ & $M S$ & $F$ \\
\hline A. ASo & 1 & 7.5385 & 3.389 \\
\hline B. DP & 1 & 15.3846 & $6.916^{*}$ \\
\hline C. DN & 1 & 16.9615 & $7.625^{* *}$ \\
\hline D. $\mathbf{A} \times \mathbf{B}$ & 1 & 0.9615 & $<1$ \\
\hline E. $A \times C$ & 1 & 1.3846 & $<1$ \\
\hline F. $\mathrm{B} \times \mathrm{C}$ & 1 & 12.4615 & $5.602 *$ \\
\hline G. $\mathrm{A} \times \mathrm{B} \times \mathrm{C}$ & 1 & 0.9615 & $<1$ \\
\hline Error & 96 & 2.2244 & \\
\hline
\end{tabular}

curacy scores for preferred person are shown. Analysis of variance (Table 12) yielded significant $F$ values for DP and DN. These show that high DP person can predict the behaviors of preferred persons more accurately than low DP, and that high DN person can predict the behaviors of preferred persons more accurately than low DN. And the effect of the ASo score was insignificant. These results support statistically our hypotheses (Hypotheses 1 $\& 2$ 2). The analysis of the interactions among the main sources revealed that only $D P \times D N$ interaction was significant. As for the $\mathrm{DP} \times \mathrm{DN}$ interaction, closer analysis of variances revealed that high $D N$ persons were significantly more accurately than low DN persons in high DP condition $(F=9.85, \quad d f=1 / 96, \quad p<.01)$, while that they were not significantly different in effectiveness in low DP condition $(F<1$, $d f=1 / 96, p>.10)$. Similarly in high DN condition high DP persons were more effective than low DP persons $(F=9.85$, $d f=1 / 96, p<.01)$, while in low DN condition high DP persons were not more effective than low DP persons $(F<1, d f=1 / 96$, $p>.10)$. These results revealed that high DP-high DN persons were more accurately than the persons of any other types.

The means and standard deviations of predictive accuracy scores for non-preferred persons are shown in Table 13. Analysis of variance (Table 14) revealed that the $F$ values for $\mathrm{DP}$, for $\mathrm{DN}$, and for $\mathrm{DP} \times \mathrm{DN}$ interaction were significant. As for the $\mathrm{DP} \times \mathrm{DN}$ interaction, closer analysis of variances revealed that high $\mathrm{DN}$ persons were significantly more accurately than low DN persons in high DP condition $(F=13.15, d f=1 / 96, \quad p<.01)$, while that they were not significantly different in effectiveness in low DP condition $(F<1$, $d f=1 / 96, p>10)$. Similarly in high $\mathrm{DN}$ condition high DP persons were more effective than low DP persons $(F=12.48$, $d f=1 / 96, p<.01)$, while in low DN condition high DP persons were not more effective than low DP persons $(F<1, d f=$ $1 / 96, p>.10)$. This result is quite same as 
TABLE 15

Means and standard deviations of intelligence quotient (IQ) (Exp. 11-2)

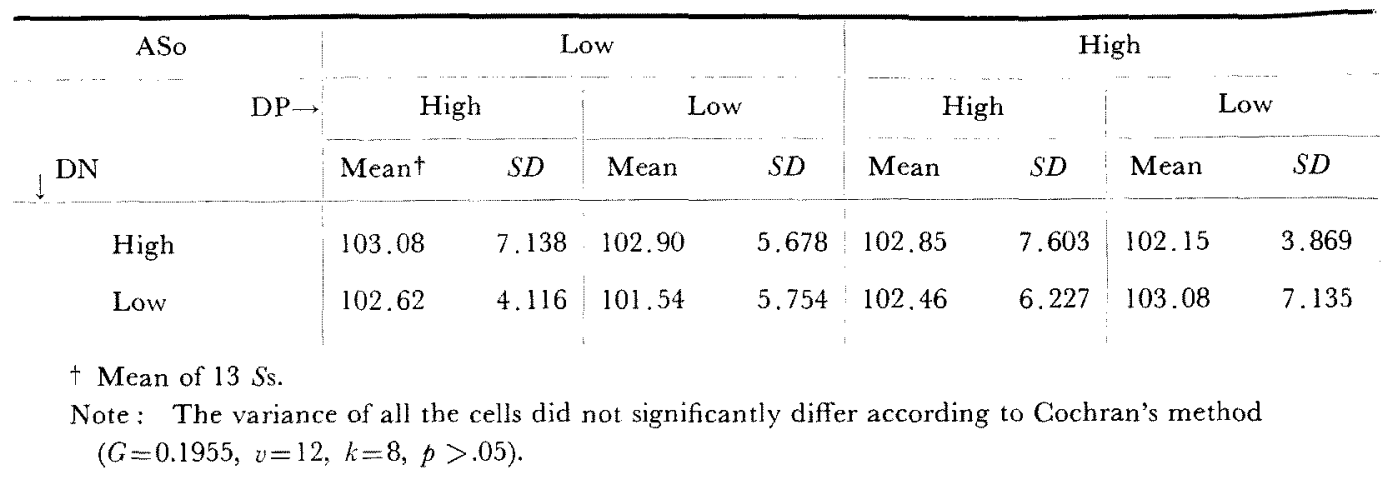

TABLE 16

Analysis of variance on means of intelligence quotient (Exp. II-2)

\begin{tabular}{l|rrr}
\hline \multicolumn{1}{c}{ Source } & $d f$ & $M S$ & $F$ \\
\hline A. ASo & 1 & 0.241 & $<1$ \\
B. DP & 1 & 2.779 & $<1$ \\
C. DN & 1 & 2.779 & $<1$ \\
D. A $\times$ B & 1 & 2.163 & $<1$ \\
E. A $\times$ C & 1 & 9.240 & $<1$ \\
F. $\mathrm{B} \times \mathrm{C}$ & 1 & 0.856 & $<1$ \\
G. A $\times \mathrm{B} \times \mathrm{C}$ & 1 & 7.471 & $<1$ \\
$\quad$ Error & 96 & 40.330 &
\end{tabular}

the result concerning the preferred persons. In general, these results supported our hypotheses concerning the predictive accuracy of both preferred and non-preferred persons' behaviors.

But, we did not find any statistically significant relationships between IQ and each of these indices (ASo, DP, \& DN) (Table 15, 16). There were hardly any relationships between $\mathrm{YG}$ personality test and these indices (Table 17). So these three indices are independent of IQ and the personality traits measured by $\mathrm{YG}$ test.

\section{Discussion}

The present results seem in general to support our hypotheses. First the persons of high DP were found to be more accurate than the persons of low DP in predicting the behaviors of his coworkers, and
TABLE 17

Correlations between three indices of cognition (ASo, DP, DN) and twelve personality characteristics in $\mathrm{YG}$ personality test (Exp. II-2)

\begin{tabular}{l|rrr}
\hline $\begin{array}{c}\text { Twelve personality } \\
\text { characteristics }\end{array}$ & ASo & DP & DN \\
Depression & -.056 & .143 & .064 \\
Cyclic tendency & -.058 & -.114 & -.051 \\
Inferiority feelings & -.180 & .171 & .037 \\
Nervousness & $-.201 *$ & .131 & -.057 \\
Lack of objectivity & -.190 & .134 & .071 \\
Lack of cooperativeness -.083 & .143 & .063 \\
Lack of agreeableness & $-.271 * *$ & .055 & .037 \\
General activity & -.059 & .061 & .092 \\
Rhathymia & .062 & -.145 & .037 \\
Thinking extroversion & .009 & -.121 & .052 \\
Ascendance & -.167 & .133 & $.207 *$ \\
Social extroversion & .111 & .055 & .031 \\
* Significant at the 0.05 level. & & \\
** Significant at the 0.01 level. & &
\end{tabular}

the result was quite the same in regard to the effects of DN-score.

But contrary to our expectation, the $F$ value for $\mathrm{DP} \times \mathrm{DN}$ interaction was also significant. The analysis of the meaning of the interaction revealed that the persons of high DP-DN could predict more accurately the behaviors of his coworkers than the persons of the other types, and that the persons whose scores were high in only one of the two indices (i.e. DP or 
DN) could not predict more accurately than the persons whose DP and DN scores were both low.

These results suggest that the cognitive mode of high DP-high DN persons differs from that of high DP-low DN and low DP-high DN persons in their psychological processes. Then what makes them differ with each other? We can't have any data to answer it. So here we propose a possible inference: high DPhigh DN persons are the persons who are able to see his coworkers soberly and objectively and to discriminate among them, whether they are preferable to him or not.

On the other hand, the persons whose scores are high in only one of the two indices are the persons who have some what stereotypic viewpoint toward preferred (or non-preferred) coworkers and evaluate them all favorably (or unfavorably). The persons who are low in both DP and DN are assumed to be the persons who adopt the stereotypic mode of interpersonal cognition in the evaluation of both preferred and non-preferred coworkers. In other words, the emotional frame of reference given by interpersonal sentiments will become more and more rigid along with the order of high DP-high DN, high DP-low DN or low DP-high DN, low DP-low DN.

We maintain that the DP and DN scores represent individual's discriminative ability and that this ability to discriminate other persons would prescribe the predictive accuracy about other persons' behaviors and abilities. As to the predictive accuracy, Bieri (1955) demonstrated that individual's cognitive complexity-simplicity (i.e. the degree of cognitive differentiation) influences strongly his predictive accuracy. Therefore it would be necessary to examine the interrelationship between the discriminative ability (in operational terms, the degree of DP and DN) and the differentiative ability (i.e. the cognitive complexity-simplicity) in regards to the predictive and leadership behaviors. It will be assumed that the two are positively related with each other.

As we had expected, it was proved that ASo could not be used as a predictor of predictive accuracy (Hypothesis 2). We maintain that ASo scores reflect mainly the affective relations between leaders and coworkers in task situations, but don't reflect the variability of their interpersonal cognitions. In this manner, the Fiedler's (1962) notion that low ASo leaders are colder and high ASo leaders are warmer can be consented to.

\section{EXPERIMENT III}

As we mentioned above, we maintain that both DP and DN of an individual reflect his discriminative ability, and the results of Experiment II-2 revealed that the persons of high DP-high DN were good at prediction of others' behaviors in comparison with the persons of low DPlow DN. These discriminative and predictive ability of an individual are assumed to play an important role in group function. That is to say, if the leader is high both in DP and DN and has a high predictive ability, he will be able to control them more appropriately. And this appropriateness of leadership behavior has a strongly positive effect on group performance. In this experiment we will examine the effects of leader's DP and DN on group performance in the "idea " task -non-competitive condition in Experiment I, in which the ASo had no effects. If we are to examine the inter-correlations between either DP or DN and ASo-Contingency Model, it should be necessary to adopt the task situations where ASo had the effects on group performances.

But we shall to examine first the simple effects of DP and DN. The hypotheses are as follows: (1) For the group performance high DP leaders would be more effective than low DP leaders. (2) For the group performance high DN leaders would be more effective than low DN leaders. 
TABLE 18

Means and standard deviations of the number of ideas as group performance (Exp. III)

\begin{tabular}{|c|c|c|c|c|c|c|c|c|c|}
\hline \multicolumn{2}{|c|}{ ASo } & \multicolumn{4}{|c|}{ Low } & \multicolumn{4}{|c|}{ High } \\
\hline \multirow[b]{2}{*}{$\downarrow^{\mathrm{DN}}$} & \multirow[t]{2}{*}{$\mathrm{DP} \rightarrow$} & & & \multicolumn{2}{|c|}{ Low } & \multicolumn{2}{|c|}{ High } & \multicolumn{2}{|c|}{ Low } \\
\hline & & Meant & $S D$ & Mean & $S D$ & Mean & $S D$ & Mean & $S D$ \\
\hline & & 55.6 & 12.7 & 39.0 & 12.3 & 78.8 & 12.2 & 38.6 & 13.2 \\
\hline & & 55.8 & 25.2 & 46.6 & 26.8 & 37.4 & 14.4 & 45.2 & 12.4 \\
\hline
\end{tabular}

+ Mean of the 5 groups.

Note: The variance of all the cells did not significantly differ according to Cochran's method $(G=0.3054, v=4, k=8, p>05)$.

There would be the interaction between DP and DN scores : that is the high DPhigh DN leaders would be more effective for group performance than the leaders of any other type. (4) ASo would have no effects on group performance.

\section{Method}

Subjects. The $S$ s were the same 160 male highschool students that were employed in Experiment II-1. $40 \mathrm{Ss}$ were the leaders and the other 120 were the followers. The 40 leaders of this experiment were consisted of each $5 S_{s}$ who were regarded as belonging respectively to one of the 8 types in Experiment II-1.

Task. Each group was assigned to two kinds of "idea" tasks which required to produce as many ideas as possible. Task A required the groups to think of the unusual uses of a brick and Task B to the unusual uses of a carton. Each group was allowed to discuss for 15 minutes for each task, and their performance was evaluated with the number of ideas produced.

Procedure. The procedure of this experiment was almost the same as that of Experiment I, but the leaders were named by the experimenter instead of being elected by group members and there were no manipulations to produce the competitive working situations. So the procedure was as follows; (1) Instruction (description of experimental task). (2) The designation of the leaders by the experimenter. (3) Giving a nickname to the group by its members. (4) Group discussion (task accomplishment).

\section{Results}

The performance of each group was evaluated by the total number of ideas produced during the two tasks. Table 18 shows the means and standard deviations of the number of ideas produced by the groups in each of the 8 conditions. Analysis of variance (Table 19) yielded significant $F$-values for $\mathrm{DP}$ and for $\mathrm{DP} \times \mathrm{DN}$ interaction. The former supports our hypothesis 1 ; that is, high DP leaders were significantly more effective for group performance than low DP leaders in "idea" task situation.

As for the $\mathrm{DP} \times \mathrm{DN}$ interaction, closer analysis of variances revealed that high DN leaders were significantly more effective than low DN leaders in high DP condition $(F=6.369, \quad d f=1 / 32, p<.05)$, while that they were not significantly different in effectiveness in low DP condition $(F<1$, $d f=1(32, p>.10)$. Similarly in high DN condition high DP leaders were more effective than low DP leaders $(F=12.100$, $d f=1 / 32, p<.01)$, while in low DN condition high DP leaders were not more effective than low DP leaders $(F<1, d f=1 / 32$, $p>.10)$. These results revealed that high $\mathrm{DP}$ - high DN leaders were more effective than the leaders of any other types, and thus strongly supported our hypothesis 
The Leader's Modes of Interpersonal Cognition and the Performance of the Group

TABLE 19

Analysis of variance on means of the number of ideas as group performance (Exp. III)

\begin{tabular}{l|rrc}
\hline \multicolumn{1}{c|}{ Source } & $d f$ & \multicolumn{1}{c}{$M S$} & $F$ \\
A. ASo & 1 & 5.625 & $<1$ \\
B. DP & 1 & 2117.025 & $6.354^{*}$ \\
C. DN & 1 & 455.625 & 1.368 \\
D. A $\times$ B & 1 & 27.225 & $<1$ \\
E. A $\times$ C & 1 & 1134.225 & 3.404 \\
F. $\mathrm{B} \times \mathbf{C}$ & 1 & 1918.225 & $5.758^{*}$ \\
G. A $\times \mathbf{B} \times \mathrm{C}$ & 1 & 1030.225 & 3.092 \\
$\quad$ Error & 32 & 333.163 &
\end{tabular}

* Significant at the 0.05 level.

(Hypothesis 3).

As to the effects of $\mathrm{DN}$, the result did not support our hypothesis (Hypothesis 2); that is, the performance of the groups under high DN leaders did not differ statistically from those of the groups under low DN leaders.

Concerning the effects of ASo (Hypothesis 4), there was not any differences in the effectiveness between the groups under high ASo leaders and those under low ASo leaders, quite the same result as in Experiment I.

\section{Discussion}

As in Experiment I, there were no effects of ASo on group performances found in this task situation.

The experimental results revealed that high DP-high DN leaders were more effective than the leaders of any other types, and that the groups conducted by the leaders of the other three types did not differ each other in their productions. These facts confirmed our inference that a leader's discriminative ability could be measured by each of his DP and DN, and that the rigidity of his emotional frame of reference could be checked by connecting these two indices.

Moreover the results of this experiment suggest the correctness of our notion that a leader's predictive ability is equivalent to his cognitive accuracy and that the appropriateness of his undertaking of leadership is expedited by his predictive ability.

Concerning the hypothesis 2 , the experimental data did not support statistically our prediction; the groups under low DN leaders were more effective than we had expected. This result seems to due to the nature of the interpersonal relations among the highschool students, though we have not the data for this reason. In general the number of the classmates that a student doesn't prefer in his class is very small. And even if he has a few non-preferred persons in his class, the degree of dislikeness can't be too extreme.

It would be probable that our experimental groups were of such interpersonal relations. Then the rigidity of the emotional frame of reference reflected on DN scores of our low DN leaders had not so much negative effects on their leadership behaviors as DP.

\section{General Discussion}

In this investigation, leader's modes of interpersonal cognition were classified into 8 types by means of three indices-ASo, DP, \& DN. According to our experiments (Experiment II, III), the leaders of these 8 types were clustered in two groups in regard to their predictive accuracy and effectiveness for group performance. One is the high DP - high DN group of leaders, and the other includes all of other types. The high DP-high DN leaders could predict more accurately than the leaders of the other types. And they were more effective in "idea" task performance.

Now let us consider the behavioral and psychological characteristics of the leaders measured by ASo, DP, and DN. First concerning ASo, Fiedler (1962) noted that low ASo leaders were cold, directive, and task-oriented, but that high ASo leaders were warm, nondirective, and memberoriented. This notion of his was not inconsistent with our results in Experiment I. 
Next concerning DP and DN, our experimental results suggest that high DPhigh DN leaders have the ability to discriminate his coworkers and recognize their variety correctly, whether they are preferred or not. This ability of high DP - high DN leaders have positive effects upon the appropriateness of his leadership behaviors and upon the performance of his group. On the other hand, high DP -low DN leaders and low DP-high DN leaders can be regarded as the leaders who have the stereotypic viewpoint toward his preferred (or non-preferred) coworkers and evaluate them uniformly favorably (or unfavorably). Low DP-low DN leaders seem to be the leaders who have the stereotypic viewpoint toward his preferred and non-preferred coworkers. Our results also revealed that this emotional frame of reference of a leader has stronger negative effects on group performance as its rigidity becomes stronger.

As far as this investigation revealed, ASoscale would be considered to reflect other aspect than DP and DN, and there is no interdependence between ASo and either DP or DN in regards to leader's effectiveness in group task situations.

But these results do suggest by no means that each of the Aso and the DP-DN should be treated separately in the leadership research, and that DP-DN could be neglected in the process of making the Aso - Contingency Model more adequate. As we stated briefly before, we aimed in the first place, in this investigation, at making leader's behavioral and psychological characteristics reflected on DP-DN score rather than examining the interrelationship be- tween ASo and DP-DN. So the systematization of the interdependency between ASo and both DP and DN must be studied in our further research.

\section{References}

BIERI, J. 1955 Cognitive complexity-simplicity and predictive behavior. 7. abnorm. soc. Psychol., 51, 263-268.

Fiedler, F. E. 1958 Leader attitudes and group effectiveness. Urbana: Univ. Illinois Press.

FIEDLER, F. E. 1962 Leader attitudes, group climate, and group creativity. J. abnorm. soc. Psychol., 65, 308-318.

FiedLeR, F. E. 1964 A contingency model of leadership effectiveness. In L. Berkowitz (Ed.), Advances in experimental social psychology. Vol. 1. New York: Academic Press, Pp. 149-190.

FredLer, F. E. 1966 The effect of leadership and cultural heterogeneity on group performance: A test of the Contingency Model. 7. exp. soc. Psychol., 1, 237-264.

FredLer, F. E. 1967 A theory of leadership effectiveness. New York: McGraw-Hill.

SHAw, M.E. 1963 Scaling group tasks: A method for dimensional analysis. Gainesville, Florida: Univ. Florida. Technical Report. No. 1. (Mimeograph).

Shaw, M. E., \& BLum, J. M. 1966 Effects of leadership style upon group performance as a function of task structure. F. pers. soc. Psychol., 3, 238-242.

Sterner, I. D. 1964 Group dynamics. In $A n-$ nual reviews of psychology. Calif.: Stanford.

Tsujtoka, B., Yatabe, T., \& Sonohara, T. 1957 A factorial study of the temperament of the Japanese college male students by the YatabeGuilford Personality Inventory. Psychologia, 1, $110-119$.

(Received March 26, 1968) 